\title{
Drying and dehydration technologies: a compact review on advance food science
}

\begin{abstract}
Foods (mostly fruits and vegetables) are dried and dehydrated to increase their usable lifetime, storage stability and minimize processing requirements and enhance transportability. Preservation techniques of foods are mostly based on drying through sunlight/solar energy methods, causing quality degradation and product contamination. Energy utilization and nature of dried items are basic parameters in the choice of drying process. An ideal drying system for the arrangement of value dried out items is savvy as it shortens the drying time and makes least contamination the item. To diminish the energy use and operational cost new measurements came up in drying procedures. This paper represents basic review on food drying techniques along with two drying methods of cranberries (microwave-vacuum and microwave-convective) and their merits and demerits regarding the quality of dried product and the process performance are evaluated.
\end{abstract}

Keywords: micro-convection, food engineering, convective food drying, heat engineering, preservation techniques, heat pump dehumidifier, superheated steam; mw-vacuum drying framework
Volume 6 Issue I - 2018

\author{
Avijit Mallik, 'Arman Arefin Md,' Sonmoy \\ Kundu, ${ }^{2}$ Al Nahian SR,' Sadman Sakif A' \\ 'Department of Mechanical Engineering, Rajshahi University of \\ Engineering and Technology, Bangladesh \\ ${ }^{2}$ Department of Botany, University of Rajshahi, Bangladesh
}

Correspondence: Avijit Mallik, Department of Mechanical Engineering, Rajshahi University of Engineering and Technology, Bangladesh,Email avijitmel3@gmail.com Received: December 01, 2017 | Published: January 12,
2018

\section{Introduction}

Foods grown from the ground are critical wellsprings of fundamental dietary supplements, for example, vitamins, minerals and fiber. Since the dampness substance of new foods grown from the ground is over $80 \%$, they are delegated profoundly perishable wares. Keeping the product fresh is the best way to keep up its wholesome esteem, yet most storage techniques require low temperatures, which are difficult to maintain all through the distribution/supply chain. Then again, drying is an appropriate option for post-harvesting particularly in South-Asian countries like Bangladesh, India, and China etc. where exist ineffectively established low temperature dispersion and handling options. It is reported that more than $20 \%$ of the world perishable food products are dried to increase shelf-life of realistic usability and advance food security. ${ }^{2}$ Organic products, vegetables and their items are dried to improve capacity dependability, limit bundling prerequisites and diminish transport weight. Regardless, in India scarcely any segment of perishables are dried which prompts huge misfortune as far as cash and work other than soak ascend in costs of wares amid the off season.

Drying of foods grown from the ground has been essentially expert by convective drying. ${ }^{3}$ There are various investigations that have tended to the issues related with ordinary convective drying. Some essential physical properties of the items have changed, for example, loss of shading, difference in surface, concoction changes influencing flavor and supplements and shrinkage. ${ }^{4}$ Plus, convective drying gives little extension for earlier re-hydration to additionally preparing subsequent to drying for a negligible quality. ${ }^{5}$ The high temperature of the drying procedure is an imperative reason for loss of value. Bringing down the procedure temperature has extraordinary potential for enhancing the nature of dried items ${ }^{6,7}$ However in such conditions, the working time and the related cost end up noticeably unsuitable. To lessen the operational cost distinctive pre-medicines and new strategy for low temperature and low energy drying techniques are developed. A concise audit of late improvement (recent years) will be talked about in the accompanying areas.

\section{Types of drying}

\section{Heat pump drying}

The utilization of heat pumps for drying has been contemplated since the mid 1950s; however the thought was mechanically attainable, it was not monetarily alluring because of the low fuel costs winning around then. By setting the evaporator of a heat direct in the fumes stream, the air leaving the dryer is cooled (in this way recuperating the sensible heat segment) and afterward dehumidified (to recoup the dormant heat) by the refrigerant. The heat in this manner added to the refrigerant is then rejected at the condenser of the heat pump to the surge of air entering the dryer, along these lines raising its temperature. At the point when the air leaving the dryer is recycle, the additional advantage of dehumidification of the drying air is likewise acknowledged, expanding its capability to accomplish better drying. Hogan et al., ${ }^{8}$ contemplated warm pump helped grain drying and presumed that the techniques were valuable because of their lower energy utilization in contact with electrically pre-heated units. ${ }^{8}$ Basically, heat pumps were utilized to lessen the energy utilization of dryers and it is currently all around concurred that heat pump dehumidifier (HPD) helped drying systems to have energy reserve units. ${ }^{9,10}$ One of the primary focal points of HPD drying is the maintenance of value and its effective application to drying esteemed heat delicate materials. Kohayakawa et al., ${ }^{11}$ depicted an investigation in which mango cuts were dried in a HPD dryer and the energy utilization of this framework was contrasted and a theoretical electrically warmed dryer. ${ }^{11}$ Figure 1 shows a typical schematic of industrial heat pump arrangement.

It is accounted for that the HPD dryer has favorable position of 22 to $40 \%$ decrease in the power utilization. Hawlader et al., ${ }^{12}$ examined dried apple, guava and potato pieces in a HPD dryer utilizing nitrogen and carbon dioxide to supplant air. The evacuation during drying appeared profitable to the items, which indicated lesser caramelizing. Moreover, the porosity and rehydration attributes of the item were predominant contrasted and material dried under vacuum. ${ }^{12}$ Gabas 
et al., ${ }^{13}$ considered drying of apple chambers in a heat pump dryer and contrasted it and items got from an electrically pre-heated dryer. The HP dryer utilized $40 \%$ less energy contrasted and the electrical warmer and at a quicker rate of drying. ${ }^{13}$ Alves-Filho et al., ${ }^{14}$ made a research on dried green peas in a fluidized bed warm draw dryer under barometrical stop drying conditions and acquired items with elevated amounts of rehydration capacity, floatability and alluring shading qualities. ${ }^{14}$ Uddin et al. ${ }^{15}$ contrasted warm pump drying and microwave and stop drying of guava, mango and honeydew melon. ${ }^{15}$

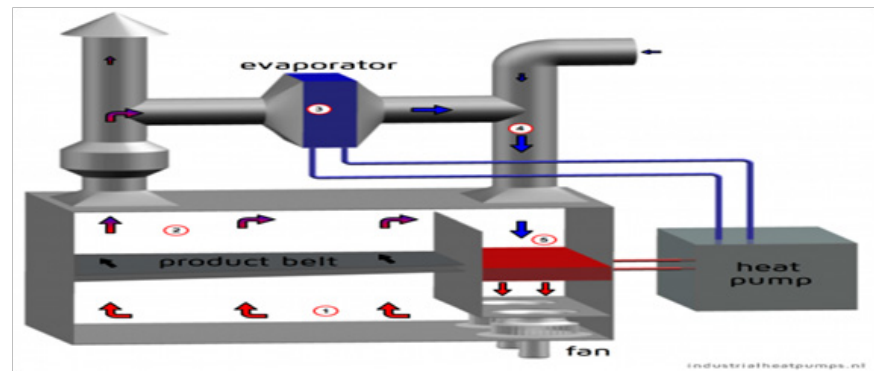

Figure I Heat pump drying for industry.

\section{Superheated steam drying}

Drying with superheated steam (SS) without air in a medium made completely out of steam. The capacity of SS to dry sustenance material is because of the expansion of sensible heat to raise its temperature over the relating captivated temperature at a given weight. It is not necessary to exhaust the evaporated water from the produce until the pressure develops beyond certain limit. Figure 2 portraits a graphical presentation of the system stated.

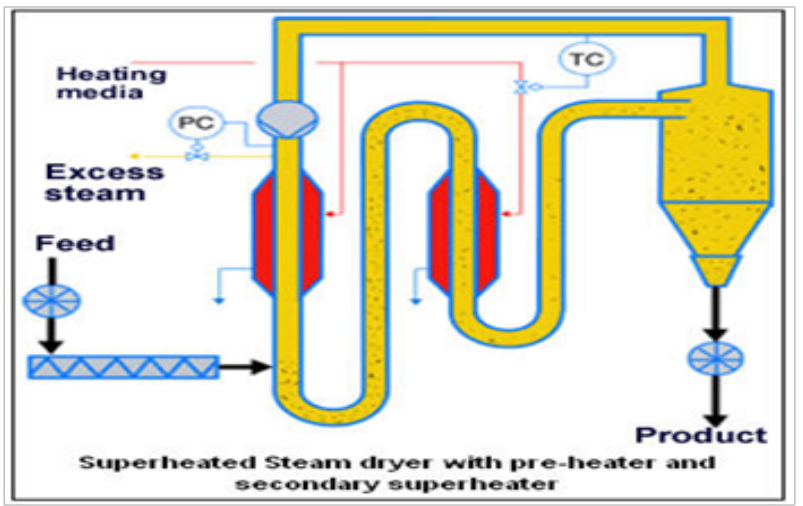

Figure 2 Superheated steam drying.

The immense preferred standpoint is that reusing of drying technique is conceivable, given extra sensible heat is included. Furthermore, any regular convection and conduction dryer could be effortlessly changed over to utilize superheated steam. ${ }^{16}$ Settled bed, fluidized bed, streak, impingement, pneumatic and splash dryers are utilizing super-warmed steam innovation for quality drying of produces.

\section{Superheated Steamed (SS) fluidized drying}

Trials demonstrate that SS drying could be adequately utilized for some, items like corn starch, potato starch and for making other results. In any case, particles those are too substantial or fine courses are difficult to dry in a fluidized bed. The model was created in view of diffusivity hypothesis and utilizations various presumptions. Among them are:

i. Buildup of water vapor on tests happens beneath the breaking point of water

ii. The greater part of the heat moved into the specimen surface is utilized for vanishing when the example temperature is equivalent to the breaking point

iii. Breaking point of water changes the weight in the neighborhood purpose of test

iv. General heat exchange coefficient on the specimen surface incorporates warm radiation from the drying medium

v. Drying process is finished when the temperature of test is higher than the breaking point of water. ${ }^{17}$

Figure 3 relays a schematic which depicts the stated system. This process is widely used on food industries.

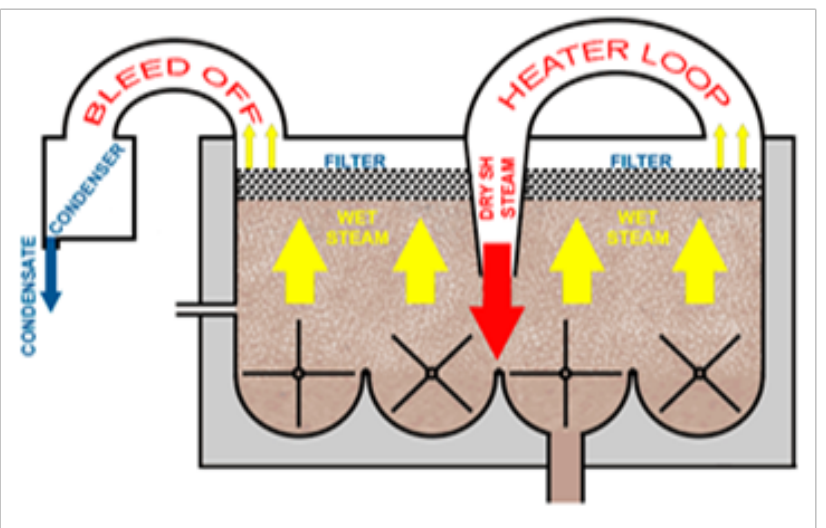

Figure 3 SS fluidized drying process for industries.

\section{Impingement drying with SS}

Despite the fact that it is primarily utilized as a part of paper industries, in the food business, air impingement is utilized for heating and cooking of items, for example, potato chips, pizza, treats and level breads. ${ }^{18}$ Low fat potato chips can be set up by this strategy. A graphical presentation of the system is given below in Figure 4.

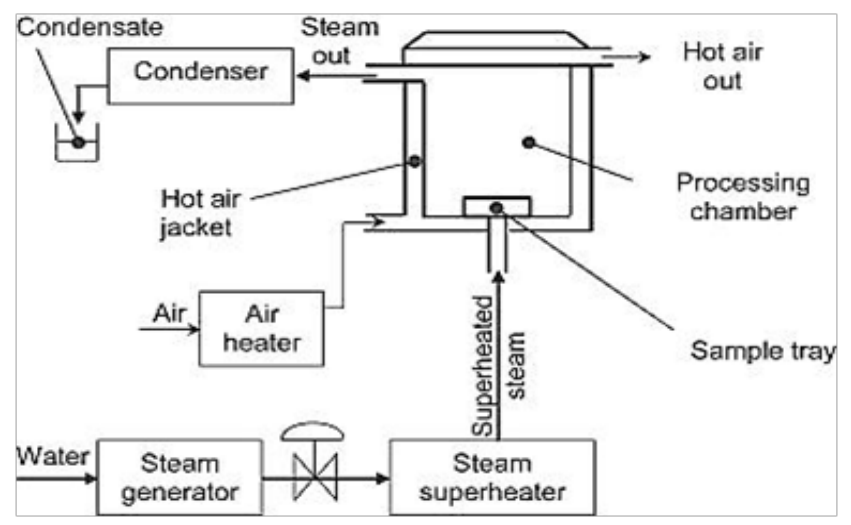

Figure 4 Impingement drying with Superheated Steam 
SS prepared potato chips held more vitamin C and were preferred in surface over air dried examples. It is watched that mass exchange was following Fick's law of dissemination and heat exchange inside potato was considered to take after Fourier's law of heat conduction. ${ }^{19}$ In any case, consideration ought to be given to the impact of SS impingement drying on item quality including shrinkage, freshness and microstructure.

\section{Microwave vacuum drying}

Additionally drying upgrades can be gotten by utilizing subatmospheric pressure. Water vanishing happens at lower temperatures under vacuum, and subsequently the product handling temperature can be essentially lower, offering higher product quality. Numerous correlations have been made between MW-vacuum drying and different frameworks, for the most part concentrating on hot air and freeze drying.

Figure 5 depicts the following system very well. The MWvacuum lack of hydration was first utilized for convergence of citrus juice. ${ }^{7-10}$ In the sustenance business, MW-vacuum drying is utilized for drying of pastas, powders, and numerous permeable solids. McDonnell Company has constructed a MW-vacuum drying framework (MIVAC) to dry grains; outright weight extending from 3.4 to $6.6 \mathrm{kPa}$ offers dampness vanishing at temperatures from 26 to $52^{\circ} \mathrm{C}$. In any case, it was not industrially fruitful because of financial aspects. Dissipated water from the item in this MW-vacuum drying ${ }^{20}$ framework is expelled for the most part by consolidating utilizing a cooling framework, nourished with water. ${ }^{21}$

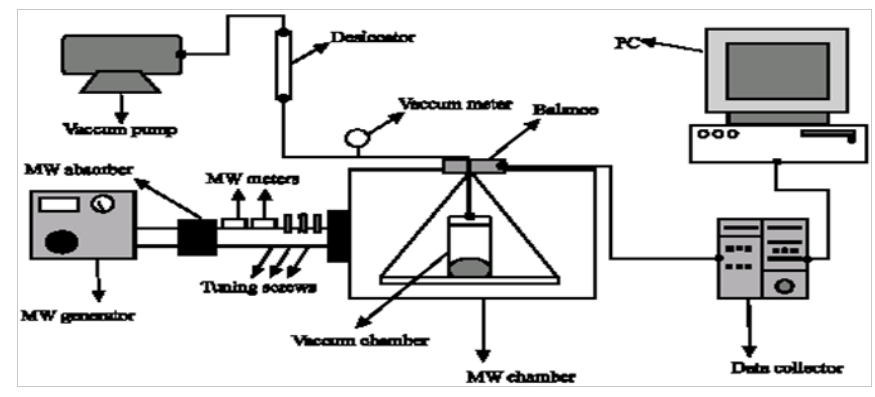

Figure 5 Microwave-vacuum drying of cranberry.

\section{Drying energy performance}

By analyzing the food drying performance it can be measured that the system of drying is economically feasible or not. Drying performance is depicted by the following equation:

$$
D E=\frac{M_{i}\left(m_{i}-m_{f}\right)}{t_{o n} P\left(1-m_{f}\right)}
$$

$\mathrm{DE}=$ Drying performance $(\mathrm{kg}$ of evaporated water/J of supplied energy)

$\mathrm{t}_{\mathrm{on}}=$ Total time of MW power-on (s)

$\mathrm{P}=\mathrm{MW}$ power input $(\mathrm{W})$

$\mathrm{m}_{\mathrm{i}}, \mathrm{m}_{\mathrm{f}}=$ Initial and final moisture contents (ratios, wet basis)

$\mathrm{M}_{\mathrm{i}}=$ Initial sample mass $(\mathrm{kg})$

Equation-(1) only considers the efficiency of MW systems; it does not consider energy required to heat air, or energy required for vacuum pump.

Pressure and power level must be correctly chosen to maximize the efficiency. Drouzas et al. $^{22}$ showed that the drying rate was significantly raised with increase of the pressure or the MW power level, but the final quality of dried banana slices was lower. The same trend was observed in Wadsworth et al. ${ }^{23}$ drying efficiency (defined as the amount of water evaporated from the sample divided by the amount of MW energy entering the drying cavity) of parboiled rice was significantly influenced by both MW power level and dryer operating pressure. One way to counter disadvantages of MW drying such as non-uniform heating is to operate in a pulsed mode, by alternating between MW power-on and power-off. This permits better redistribution of the temperature and the moisture profile within the product during power-off times. For a given product, the MW poweron time and the pulsing ratio should be optimized. Pulsed application of MW energy combined with vacuum to dry cranberries has been found more efficient than continuous application. ${ }^{24}$ In pulsed mode, shorter power-on time and longer power off time provided a higher drying efficiency, where the energy utilization coefficient (defined as a ratio of energy absorbed by the sample and energy absorbed by the same mass of distilled water) pulsed mode ranged from 0.53 to 0.95 , and for continuous MW application it was significantly lower, ranging from 0.43 to 0.67 . Concerning the quality properties, continuously dried samples had a higher redness and undesirable tougher texture than the samples dried with pulsed mode.

\section{Influence on storage on quality}

A huge loss of supplements happens in dried foods grown from the ground amid capacity. This misfortune relies upon capacity temperature, $\mathrm{pH}$, and presentation to oxygen, porosity, light and nearness of natural acids. The degree of misfortunes relies upon the sort of vitamins and capacity conditions, for example, the presentation to oxygen and light. ${ }^{25}$ Amid capacity of spaghetti, for instance, no loss of thiamine and niacin was watched yet riboflavin was defenseless to temperature, stockpiling period and light.

In a few circumstances the strategy for lack of hydration can likewise impact the loss of supplements. For example, Kaminski et al. ${ }^{26}$ watched a quick debasement of carotenoids in solidify dried carrots. They watched that air-drying was more effective for carotene conservation when put away at encompassing temperature. Stop dried items are for the most part more permeable. This encourages oxygen exchange and advances fast oxidation of carotene. ${ }^{26} \mathrm{Cinar}^{27}$ revealed that the most noteworthy shade misfortune was in carrot put away at $40^{\circ} \mathrm{C}(98.1 \%)$ while the least misfortune was in sweet potato kept at $4^{\circ} \mathrm{C}(11.3 \%)$ amid 45 days of capacity. ${ }^{27}$

\section{Ways to reduce energy consumption}

Routine care in operation ought to dependably frame a basic piece of yield dryer operation. Mix-drying, another most ideal approach to decrease the energy consumption expanding the through-put and enhances quality. ${ }^{27}$ Improvement of vitality through scientific displaying is another critical approach to lessen vitality utilization. ${ }^{28}$ Irregular drying and electro drying advances are likewise used to diminish vitality utilization. The utilization of microwave was found to majorly affect both the drying time and the vitality utilization. ${ }^{29}$ The particular vitality utilization for the drying of grapes diminished from $81.15 \mathrm{MJ} / \mathrm{kg}$ if there should arise an occurrence of convective 
drying to $7.11-24.32 \mathrm{MJ} / \mathrm{kg}$ by joined microwave-convective drying. ${ }^{30}$ Infrared-convective dryers lessen the vitality utilization of osmotically pre-treated examples of potato and pineapple. Warmth pump dryers and high electric field dryers have the immense potential for modern application, especially for high esteem crops as a result of prevalent nature of its items, effortlessness of plan and low vitality utilize. ${ }^{31}$

\section{Conclusion}

Numerous new measurements came up in drying innovation to diminish the vitality use and operational cost. Among the advances, osmotic lack of hydration, vacuum drying, solidify drying, SS drying, HPD drying microwave drying and shower drying are putting forth incredible breadth for the generation of best quality dried items and powders. Due to their specific and clinometric warming impacts, microwaves bring new attributes, for example, expanded rate of drying, upgraded last item quality and enhanced vitality utilization. The nature of microwave dried wares is regularly between air-dried and solidifies dried items. In this way, savvy interchange frameworks like blend/half and half drying ought to be elevated to harvest the benefit of modern drying frameworks with least cost and straightforward advances. Mix drying with an underlying traditional drying process took after by a microwave complete or microwave vacuum process has demonstrated to decrease drying time while enhancing item quality and limiting vitality prerequisites. Notwithstanding, a few components ought to be mulled over when creating drying framework for the leafy foods. An ideal drying framework for the protection of foods grown from the ground ought to be practical, shorter drying time and with least harm to the item.

\section{Acknowledgements}

I would just like to acknowledge all the teachers of Dept. of Mechanical Engineering, Rajshahi university of Engineering \& Technology, Bangladesh for their help and support.

\section{Conflict of interest}

There is no conflict of interest or business purpose in this research.

\section{References}

1. Orsat, Valérie, Viboon Changrue, GS Vijaya Raghavan. Microwave drying of fruits and vegetables. Stewart Post-Harvest Rev. 2006;6:4-9.

2. Grabowski S, Marcotte M, Ramaswamy HS. Drying of fruits, vegetables, and spices. In: Chakraverty A, et al. editors. Handbook of Postharvest Technology: Cereals, Fruits, Vegetables, Tea, and Spices. New York, USA: CRC press; 2003. p. 653-695.

3. Nijhuis HH, Torringa HM, Muresan S, et al. Approaches to improving the quality of dried fruits and vegetables. Tr Food Sci Technol. 1998;9:13-20

4. Azzouz S, Hermassi I, Chouikh R, et al. The convective drying of grape seeds: Effect of shrinkage on heat and mass transfer. Journal of Food Process Engineering. 2017;41(1).

5. Joardder, Mohammad UH, Chandan Kumar, et al. "Food structure: Its formation and relationships with other properties. Critical reviews in food science and nutrition. 2017;57(6):1190-1205.

6. Rajkumar Gomathi, Shanmugham Saravanan, Mercia de souse Galvao, et al. Comparative evaluation of physical properties and volatiles profile of cabbages subjected to hot air and freeze drying. Drying Technology. 2017;35(6):699-708
7. Beaudry C, Raghavan GSV, Ratti C, et al. Effect of four drying methods on the quality of osmotically dehydrated cranberries. Drying Technol. 2004;22(3):521-539

8. Hogan MR, Ayers DL, Muller Jr RE, et al. Heat pump for low-temperature grain drying. Trans ASAE. 1983;26(4):1234-1238

9. Queiroz R, Gabas AL, Telis VRN. Drying kinetics of tomato by using electric resistance and heat pump dryers. Drying Technol. 2004;22(7):1603-1620.

10. Seco JIF G, Seco JJF G, Prieto EH, et al. Evaluation at industrial scale of electric-driven heat pump dryers (HPD). Holz Roh Werkst. 2004;62(4):261-267

11. Kohayakawa MN, Silveira-Júnior V, Telis-Romero J. Drying of mango slices using heat pump dryer. Proc $14^{\text {th }}$ Int Drying Symp, Vol B, São Paulo, Brazil; 2004. p. 884-891.

12. Hawlader MNA, Perera CO, Tian M. Properties of modified atmosphere heat pump dried foods. J Food Eng. 2006;74(3):392-401.

13. Gabas AL, Bernardi M, Telis-Romero J, et al. Application of heat pump in drying of apple cylinders. Proc $14^{\text {th }}$ Int Drying Symp, Vol C, São Paulo, Brazil, 22-25 August; 2004. p. 1922-1929.

14. Alves Filho O, García Pascual P, et al. Dehydration of green peas under atmospheric freeze-drying conditions. Proc 14th Int Drying Sym, Vol C, Sao Paulo, Brazil, 22-25 August; 2004. p. 1521-1528.

15. Uddin MS, Hawlader MNA, Hui X. A comparative study on heat pump microwave and freeze drying of fresh fruits. Proc 14th Int Drying Symp, 22-25 August, Vol C, São Paulo: Brazil; 2004. p. 2035-2042.

16. Tatemoto Y, Yano S, Mawatart Y, et al. Drying characteristics of porous material immersed in a bed glass beads fl uedized by superheated steam under reduced pressure. Chem Eng Sci. 2007;62:471-480

17. Jiang, Zhaochen, Andreas Bück, et al. "CFD-DEM study of residence time, droplet deposition, and collision velocity for a binary particle mixture in a Wurster fluidized bed coater. Drying Technology. 2017. p. 1-13.

18. Rahman MS, Labuza TP. Water activity and food preservation. In Handbook of food preservation. Rahman MS editor. New York, USA: Marcel Dekker; 1999. p. 339-382.

19. Leeratamark N, Devahastio S, Chiewchan N. Drying kinetics and quality of potato chips undergoing different drying techniques. J Food Eng. 2006;77(3):635-638.

20. Aydinkaptan E, Barutçu Mazi I. Monitoring the physicochemical features of sunflower oil and French fries during repeated microwave frying and deep-fat frying. Grasas y Aceites. 2017;68(3):202.

21. Sanga E, Mujumdar AS, Raghavan GSV. Principles and applications of microwave drying. Drying Technology in Agriculture and Food Sciences. 2000;(2000):253-289.

22. Drouzas AE, Tsami E, Saravacos GD. Microwave/vacuum drying of model fruit gels. Journal of Food Engineering. 1999;39(2):117-122.

23. Wadsworth JI Velupillai L, Verma LR. Microwave-vacuum drying of parboiled rice. Transactions of the ASAE. 1990;33(1):199-0211.

24. Yongsawatdigul J, Gunasekaran S. Microwave $\square$ vacuum drying of cranberries: Part I. Energy use and efficiency. Journal of Food Processing and Preservation. 1996;20(2):121-143.

25. Sablani, Shyam S. Drying of fruits and vegetables: retention of nutritional/functional quality. Drying technology. 2006;24(2):123-135.

26. Kaminski E. Effect of drying and storage of dried carrots on sensory characteristics and volatile constituents. Die Nahrung Food. 1986. 
27. Çinar, Inci. Carotenoid pigment loss of freeze-dried plant samples under different storage conditions. LWT-Food Science and Technology. 2004;37(3):363-367.

28. Tippayawong NC, Tantakitti, Thavornun S. Energy efficiency improvements in longan drying practice. Energy. 2008;33(7):1137-1143.

29. Orsat V, Raghavan V, Meda V. Microwave technology for food processing an overview. The microwave processing of foods. 2005;(2005):105-118
30. Tulasidas TN, Raghavan GSV, Mujumdar AS. Microwave Drymg of Grapes in a Single Mode Cavity at 2450 Mhz-i: Drying Kinetics. Drying Technology. 1995;13(8-9):1949-1971.

31. Corrêa JLG, Rasia MC, Mulet A, et al. Influence of ultrasound application on both the osmotic pretreatment and subsequent convective drying of pineapple (Ananas comosus). Innovative Food Science \& Emerging Technologies. 2017;41:284-291. 